\section{POS0988 FACTORS ASSOCIATED WITH PAIN INTENSITY IN AXIAL SPONDYLOARTHRITIS. RESULTS FROM THE EUROPEAN MAP OF AXIAL SPONDYLOARTHRITIS (EMAS)}

M. Garrido-Cumbrera ${ }^{1}$, V. Navarro-Compán ${ }^{2}$, C. Bundy ${ }^{3}$, L. Christen ${ }^{4}$, R. Mahapatra ${ }^{5}$, S. Makri ${ }^{6}$, C. J. Delgado-Domínguez', J. Correa-Fernández ${ }^{1}$, P. Plazuelo-Ramos ${ }^{7}$, D. Poddubnyy ${ }^{8}$ on behalf of IMAS working group. ${ }^{1}$ Universidad de Sevilla, Health \& Territory Research (HTR), Sevilla, Spain; ${ }^{2}$ Hospital Universitario La Paz, IdiPaz, Madrid, Spain; ${ }^{3}$ Cardiff University, School of Healthcare Sciences, Cardiff, United Kingdom; ${ }^{4}$ Novartis Pharma AG, Patient Engagement, Basel, Switzerland; ${ }^{5}$ Axial Spondyloarthritis International Federation (ASIF), Patient Advocacy, London, United Kingdom; ${ }^{6}$ Cyprus League Against Rheumatism (CYPLAR), Patient Advocacy, Nicosia, Cyprus; ${ }^{7}$ Spanish Federation of Spondyloarthritis Associations (CEADE), Presidency, Madrid, Spain: ${ }^{8}$ Charité - Universitätsmedizin Berlin, Rheumatology Department, Berlin, Germany

Background: Pain is a hallmark of axial spondyloarthritis (axSpA) and can significantly deteriorate patients' health status.

Objectives: This analysis aims to investigate factors associated with pain intensity in a large sample of European axSpA patients.

Methods: 2,846 unselected patients participated in EMAS, a cross-sectional study (2017-2018) across 13 European countries. Data from 2,636 participants who reported pain were analysed. Pain was measured by the mean of two BASDAI questions (range 0 "no pain" to 10 "most severe pain"): "How would you describe the overall level of AS neck, back or hip pain you have had?" and "How would you describe the overall level of pain/swelling in joints other than neck, back, hips you have had?". Linear regression analysis was applied to identify associations between pain intensity and sociodemographic factors, patient-reported outcomes [BASDAI (0-10), spinal stiffness (3-12), functional limitation (0-54), mental health using the 12-item General Health Questionnaire GHQ-12 (0-12)], work life, physical activity and comorbidities, for which 850 patients were included.

Results: The mean age of the sample was 44 years, $61.4 \%$ were female, $49.4 \%$ had a university degree and $67.7 \%$ were married. The average reported pain intensity was $5.3( \pm 2.2) ; 76.2 \%$ reported pain intensity $\geq 4$, with the greatest intensity reported by women ( 5.5 vs $4.9, p<0.001$ ), those not university educated (5.6 vs $5.0, p<0.001$ ), separated or divorced compared to singles (5.8 vs 5.2 , $\mathrm{p}=0.004$ ), and not physically active (5.7 vs $5.2, \mathrm{p}<0.001$ ). In addition, employed patients who experienced work-related issues reported greater pain (5.2 vs 3.9) as did those who experienced/ believed they would face difficulties finding work due to axSpA (5.9 vs 4.3), and those whose employment choice was determined by axSpA ( 5.7 vs 4.9 ; all $p<0.001)$. Moreover, associations with anxiety ( 5.9 vs 5.0 ), depression ( 6.1 vs 5.0 ) and sleep disorders (5.9 vs 4.9 ; all $p<0.001$ ) were also found. The multiple linear regression model showed that those with higher pain intensity reported at least one work-related issue $(B=0.65)$, difficulties finding work due to axSpA $(B=0.48)$, not having attended university $(B=0.38)$, greater spinal stiffness $(B=0.29)$, being female $(B=0.26)$ and poorer mental health (GHQ-12) $(B=0.10)($ Table 1).

Table 1. Regression analysis of the variables associated with pain intensity (0-10 NRS), $\mathrm{n}=850$

\begin{tabular}{|c|c|c|c|c|}
\hline & \multicolumn{2}{|c|}{ Univariable } & \multicolumn{2}{|c|}{ Multivariable } \\
\hline & B & $95 \% \mathrm{Cl}$ & B & $95 \% \mathrm{Cl}$ \\
\hline Gender. Female ${ }^{1}$ & 0.604 & $0.432,0.775$ & 0.260 & $0.003,0.517$ \\
\hline Educational level. No University ${ }^{2}$ & 0.671 & $0.504,0.838$ & 0.376 & $0.118,0.634$ \\
\hline Marital Status. Divorced/Separated ${ }^{3}$ & 0.495 & $0.209,0.780$ & -0.044 & $-0.468,0.380$ \\
\hline Body Mass Index. Obese ${ }^{4}$ & 0.362 & $-0.097,0.821$ & NA & NA \\
\hline GHQ-12 (0-12) & 0.182 & $0.163,0.201$ & 0.100 & $0.064,0.137$ \\
\hline Functional Limitation (0-54) & 0.036 & $0.030,0.041$ & 0.009 & $-0.001,0.018$ \\
\hline Spinal Stiffness (3-12) & 0.357 & $0.326,0.388$ & 0.288 & $0.234,0.342$ \\
\hline Diagnostic Delay, years & 0.020 & $0.010,0.030$ & -0.015 & $-0.032,0.002$ \\
\hline Work-Related Issues. Yes & 1.338 & $1.095,1.582$ & 0.654 & $0.338,0.970$ \\
\hline Difficulty finding job due to axSpA. Yes & 1.568 & $1.362,1.774$ & 0.476 & $0.176,0.776$ \\
\hline Work choice determinate by axSpA. Yes & 0.808 & $0.633,0.983$ & 0.199 & $-0.069,0.467$ \\
\hline Physical activity. No & 0.494 & $0.263,0.725$ & -0.128 & $-0.497,0.242$ \\
\hline Anxiety diagnosis. Yes & 0.935 & $0.753,1.117$ & -0.047 & $-0.416,0.321$ \\
\hline Depression diagnosis. Yes & 1.107 & $0.919,1.295$ & 0.115 & $-0.270,0.500$ \\
\hline Sleep disorder diagnosis. Yes & 1.042 & $0.871,1.213$ & -0.091 & $-0.392,0.211$ \\
\hline
\end{tabular}

${ }^{1}$ Female vs Male; ${ }^{2}$ No university studies (no schooling, primary and high school) vs University studies; ${ }^{3}$ Divorced/separated vs single, married and widow; ${ }^{4}$ Obese vs not obese (underweight, normal and overweight).
Conclusion: Pain was most strongly associated with working life impairment, as well as with spinal stiffness. Pain was also associated with suffering from depression, anxiety and sleep disorders. Understanding how pain affects individuals and shared-decision making between rheumatologists and patients are essential for long-term disease management and preserving quality of life of axSpA patients.

Acknowledgements: This study was supported by Novartis Pharma AG The authors would like to thank all patients who participated in the EMAS study.

Disclosure of Interests: Marco Garrido-Cumbrera: None declared, Victoria Navarro-Compán Grant/research support from: Abbvie, BMS, Lilly, MSD Novartis, Pfizer, Roche, and UCB, Christine Bundy Consultant of: Abbvie, Celgene, Janssen, Lilly, Novartis, and Pfizer, Laura Christen Employee of: Novartis Pharma AG, Raj Mahapatra: None declared, Souzi Makri: None declared, Carlos Jesús Delgado-Domínguez: None declared, José Correa-Fernández: None declared, Pedro Plazuelo-Ramos: None declared, Denis Poddubnyy Consultant of: Abbvie, BMS, Celgene, Janssen, Lilly, MSD, Novartis, Pfizer, Roche, and UCB, Grant/research support from: Abbvie, MSD, Novartis, and Pfizer.

DOI: 10.1136/annrheumdis-2021-eular.2439

\begin{tabular}{|l|l}
\hline POS0989 & FACTORS ASSOCIATED WITH INABILITY TO \\
WORK AND DISABILITY IN PATIENTS WITH AXIAL \\
SPONDYLARTHRITIS. RESULTS FROM THE \\
EUROPEAN MAP OF AXIAL SPONDYLOARTHRITIS \\
(EMAS)
\end{tabular}

M. Garrido-Cumbrera ${ }^{1}$, C. Bundy², V. Navarro-Compán ${ }^{3}$, L. Christen ${ }^{4}$, R. Mahapatra ${ }^{5}$, S. Makri' ${ }^{6}$, C. J. Delgado-Domínguez ${ }^{1}$, D. Gálvez-Ruiz ${ }^{1}$, P. Plazuelo-Ramos ${ }^{7}$, D. Poddubnyy ${ }^{8}$ on behalf of IMAS working group. ${ }^{1}$ Universidad de Sevilla, Health \& Territory Research (HTR), Seville, Spain; ${ }^{2}$ Cardiff University, School of Healthcare Sciences, Cardiff, United Kingdom ${ }^{3}$ Hospital Universitario La Paz, IdiPaz, Madrid, Spain; ${ }^{4}$ Novartis Pharma AG, Patient Engagement, Basel, Spain; ${ }^{5}$ Axial Spondyloarthritis International Federation (ASIF), Patient Advocacy, London, United Kingdom; ${ }^{6}$ Cyprus League Against Rheumatism (CYPLAR), Patient Advocacy, Nicosia, Cyprus; ${ }^{7}$ Spanish Federation of Spondyloarthritis Associations (CEADE), Presidency, Madrid, Spain; ${ }^{8}$ Charité - Universitätsmedizin Berlin, Rheumatology Department, Berlin, Germany

Background: Axial spondyloarthritis (axSpA) is associated with a high burden of disease, which may lead to inability to work and disability.

Objectives: This analysis aims to identify factors associated with inability to work and disability among European axSpA patients.

Methods: Data from 2,846 unselected patients participating in EMAS, a cross-sectional study (2017-2018) across 13 European countries were analysed. The sample was divided into those on permanent sick leave or with a recognised disability (Group 1) and those with neither permanent sick leave nor a recognized disability (Group 2). Mann-Whitney and Pearson's $\chi^{2}$ tests were used to analyse possible differences between groups regarding sociodemographic characteristics, patient-reported outcomes [BASDAI (0-10), GHQ-12 (0-12), functional limitation (0-54) and spinal stiffness (3-12)], lifestyle habits, working life, and comorbidities). Univariable and multivariable binary logistic regression were used to analyse variables possibly explaining being on permanent sick leave and disability, for which 1,657 patients were included.

Results: Mean age was 43.9 years, $61.3 \%$ were female, $48.1 \%$ had a university degree, and $67.9 \%$ were married. Patients in Group $1(34.4 \%$; $n=978)$ were more likely to be women $(54.3 \%)$, married $(71.1 \%)$, with higher disease activity (BASDAI 5.9 vs. 5.3 ), functional limitation (25.1 vs. 18.0 ), spinal stiffness (8.6 vs. 7.3 ; all $p<0.001)$, and longer diagnostic delay ( 8.1 vs 7.1 years; $p=0.01$ ) than those in Group $2(65.6 \% ; n=1,868)$. In addition, $88.0 \%$ of Group $1(n=728)$ had difficulties in finding a job due to axSpA throughout life; and more than $30.0 \%$ reported a diagnosis of anxiety, depression, or sleep disorders. Moreover, being in Group 1 was associated with higher functional limitation in all daily activities. In the multivariable binary logistic regression, the qualitative variables associated with permanent sick leave or disability were: difficulties finding work $(\mathrm{OR}=2.52)$, belonging to a patient organisation $(\mathrm{OR}=1.54)$ and work choice determined by axSpA $(\mathrm{OR}=1.38)$. The quantitative variables associated with permanent sick leave or disability were: higher spinal stiffness $(O R=1.09)$, older age $(O R=1.03)$, longer disease duration $(\mathrm{OR}=1.03)$, shorter diagnostic delay $(\mathrm{OR}=0.98)$, and higher functional limitation $(\mathrm{OR}=1.01)$ (Table 1). 